\title{
Duration of Sick Leave, Patient's Postoperative Satisfaction and Impairment of Daily Living after Open Abdominal Myoma Enucleation in Dependence on Myoma Size
}

\author{
Krankschreibungsdauer, postoperative Patientinnenzufriedenheit und Beeinträchtigung der Lebensführung \\ nach abdominal-offener Myomenukleation in Abhängigkeit von der Myomgröße
}

Authors

Affiliations

\section{T. Kalthofen ${ }^{1}$, R. W. Krätschell ${ }^{2}$, M. David ${ }^{2}$}

${ }^{1}$ Internal Medicine, Schlosspark-Klinik, Berlin

${ }^{2}$ Klinik für Gynäkologie, Charité Campus Virchow-Klinikum, Berlin
Deutschsprachige Zusatzinformationen online abrufbar unter: www.thieme-connect.de/ ejournals/toc/gebfra

\section{received $\quad 15.12 .2014$ \\ revised 11.2.2015 \\ accepted 18.2.2015}

Bibliography

Dol http://dx.doi.org/

10.1055/s-0035-1546051

Geburtsh Frauenheilk 2015; 75 : 450-455 ๑ Georg Thieme Verlag KG Stuttgart · New York . ISSN 0016-5751

\section{Correspondence}

Prof. Matthias David

Charité Campus

Virchow-Klinikum

Klinik für Gynäkologie

Augustenburger Platz 1

13353 Berlin

matthias.david@charite.de

\section{Abstract}

$\nabla$

Purpose: What is the average duration of sick leave and the postoperative impairment to daily living in dependence on the size of the removed myoma? Does patient satisfaction depend on the size of the removed myoma? Is there a difference in the rate of improvement of symptoms depending on the size of the myoma?

Patient Collective: This is a retrospective survey of the data of 377 consecutive female patients treated for symptomatic uterus myomatosus by open abdominal myoma enucleation between 2 / 2002 and 12/2009; the number of removed myomas, myoma size and localisation, myoma-associated complaints, length of sick leave, postoperative impairments of daily living and scar length were assessed.

Results: The response rate amounted to $61 \%$ (230/377 patients). The average sick leave of patients with a myoma diameter $\geq 10 \mathrm{~cm}$ was 1.5 days shorter than that for patients with myomas $<10 \mathrm{~cm}$. Depending on the symptoms between 7 and $75 \%$ of the patients reported an improvement of their complaints. For those patients with myomas $>10 \mathrm{~cm}$ the proportion with an improvement in symptoms was smaller than that for the patients with smaller myomas - exception "feeling of pressure in the bladder".

Conclusions: Even for relatively large myomas, the quality of life is not impaired more strongly or for longer periods than that after removal of smaller myomas. Activities of daily life are impaired for about 4 weeks.

\section{Zusammenfassung \\ $\nabla$}

Fragestellung: Wie ist die durchschnittliche Krankschreibungsdauer und Beeinträchtigung des täglichen Lebens postoperativ je nach Größe des entfernten Myoms? Hängt die Patientinnenzufriedenheit von der Größe des entfernten Myoms ab? Unterscheidet sich die Häufigkeit der Beschwerdebesserung in Abhängigkeit von der Myomgröße?

Patientinnenkollektiv: Monozentrische retrospektive Datenauswertung von 377 konsekutiv von 2/2002 bis 12/2009 wegen eines symptomatischen Uterus myomatosus mittels abdominaloffener Myomenukleation operierten Frauen; Erfassung der Anzahl der entfernten Myome, Myomgröße und -lokalisation, myomassoziierten Beschwerden, Krankschreibungsdauer, postoperativen Beeinträchtigung der täglichen Lebensführung, Narbenlänge.

Ergebnisse: Die Rücklaufquote betrug 61\% (230/ 377 Pat.). Patientinnen mit einem Myomdurchmesser $\geq 10 \mathrm{~cm}$ waren 1,5 Tage kürzer krankgeschrieben als die Patientinnen mit Myomen $<10 \mathrm{~cm}$. Eine Beschwerdebesserung gaben, je nach Symptom, 7 bis 75\% der Patientinnen an. Bei den Patientinnen mit Myomen $>10 \mathrm{~cm}$ war der Anteil von Frauen mit Symptombesserung geringer als bei den Patientinnen mit kleineren Myomen - Ausnahme „Druckgefühl auf die Blase“.

Schlussfolgerungen: Auch bei relativ großen Myomen ist nach abdominal-offener Enukleation die Lebensqualität nicht stärker oder länger gemindert als bei der Entfernung kleinerer Myome. Die tägliche Lebensführung ist für etwa 4 Wochen beeinträchtigt. 


\section{Introduction}

\section{$\nabla$}

Frequently asked questions by female patients on release from hospital are: How long will I be on sick leave? When can I resume my normal activities of daily life? The physicians' answers to these questions are often not evidence based but in the best case the result of previous experience. Nevertheless, internationally only few studies have dealt with changes in quality of life before and after gynaecological operations. Thus, Reitsma et al. (2011) in Canada prospectively examined 460 women undergoing planned gynaecological operations by means of a questionnaire on quality of life prior to as well as 6 weeks and 6 months after a laparotomy [1]. In comparison with normal data, the women had prior to and six weeks after the operation a reduced quality of life in practically all scales of the employed questionnaire, whereas the values recorded at 6 months after operation showed no differences to those of a non-operated collective [1]. Larger systematic studies on postoperative recovery after gynaecological operations through to regaining the ability to work or, respectively, complete recovery of the patient are as yet not available in Germany.

Myomas are assumed to exist in up to $50 \%$ of all women of childbearing age, and cause clinical symptoms in $25-30 \%$ of them [2, $3]$. Exact details on the prevalence, however, are also not available in Germany. Except for the constellation fertility impairment/desire to have children, a patient needs treatment only when myoma-related complaints arise. Choice of the correct therapy depends not only on medical but also on socio-demographic factors. The complaints caused by myomas can lead to appreciable impairments in the quality of life $[4,5]$. In the treatment of uterine myomas the primary objective is to improve the patient's quality of life as well as, in uterus-conserving procedures, the retention or even improvement of fertility. Apart from the actual medical success of the operation (complete removal of the myoma, complication free course) a measure for the success of a treatment method is the patient's satisfaction.

A broad spectrum of therapeutic options is available today for the treatment of myomas [6]. Therapeutic success and patient satisfaction with the new treatment procedures such as embolisation (UAE) and focused ultrasound (MRgFUS/HIFUS) are topics of intensive research $[7,8]$. Also studies on the postoperative mental condition and satisfaction of patients after hysterectomy have been reported [9]. Studies with these objectives on open abdominal myoma removal are not available in the current literature. The size and localisation of myomas are in principle, not limiting factors for myoma enucleation by laparotomy, and this approach is frequently chosen in cases with one or several larger and/or deep lying intra- or, respectively, transmural myomas [10]. In the focus of the following investigation are patients with a myo$\mathrm{ma} \geq 10 \mathrm{~cm}$. The objective of this evaluation was, by means of a combination of retrospective clinical data and assessment of pre- and postoperative patient surveys, to find answers to the following questions:

1. How long is the average period of sick leave and what is the average postoperative impairment to activities of daily life in dependence on the size of the removed myoma?

2. Is there a relationship between size of the removed myoma and the postoperative satisfaction of the patient?

3. Are there differences in the frequency of improvement of complaints after surgery in dependence on the size of the myoma?

\section{Patients and Methods}

\section{$\nabla$}

\section{Patient collectives}

The data of 377 women who were operated by means of an open abdominal myoma enucleation due to symptomatic uterus myomatosus and/or a (suspected) impaired fertility at the department of gynaecology, Charité University Medical Hospital Berlin, Campus Virchow-Clinic between February 2002 and December 2009 were retrospectively evaluated. The preoperative diagnoses were made almost exclusively in the myoma consulting office of the same hospital by means of ultrasonography. The indication for surgical treatment (laparotomy) was in each case the deep intramural location of the dominating myoma or of a single large myoma. For all patients the myoma operation was performed by the same surgeon (M.D., 15-20 years professional experience at the time of the study) always in the same manner.

\section{Investigated parameters}

Number of removed myomas, dimensions of the - largest/dominant - myoma (diameter from the pathological report whereby tissue shrinkage due to fixation of about $4.5 \%$ was assumed according to [11]) and localisation of the - largest/dominant - myoma were taken from the records of each individual patient. In addition, a series of intra- and postoperative parameters was recorded.

Most of the patients had presented preoperatively at the myoma consulting office of the Charité/Campus Virchow clinic and had filled out the case history questionnaire which was developed and has been in use for several years in the clinic, this included their personal appraisal of the possibly myoma-related symptoms. With the help of this questionnaire eight symptoms could be evaluated by means of a Likert scale of $0-10(0=$ no complaints through to 10 = maximal complaints): severity of bleeding, premenstrual pain, pain during period, pain during sexual intercourse, back pain, pressure in the bladder, feeling of pressure/foreign body in lower abdomen, and constipation.

For evaluation of the postoperative course after release from hospital, a two-page questionnaire was developed for use in telephone interviews. If the patients could not be reached by telephone this questionnaire was sent to them by post. The questionnaire included among others items about length in days of sick leave after myoma enucleation and the duration of impairments in activities of daily life in weeks or, respectively, days as well as length of the scar (as measured by the patient and reported in $\mathrm{cm})$. Three variables were recorded in order to assess the postoperative satisfaction of the patients:

1. Well-being* related to myoma complaints in comparison to the period directly prior to the operation,

2. General health satisfaction* (for parameters $1^{*}$ and $2^{*}$ each with a scale from $0=$ not at all good to $10=$ maximally good),

3. Would you recommend the operation to a friend (possible answers: yes, no, don't know).

In addition, as in the questionnaire used preoperatively, the patients were also asked postoperatively to assess their current complaints on the basis of the same eight Likert symptom scales.

\section{Statistical evaluation}

The most important parameter of the data analysis was the size of the myoma, this was followed accordingly by a comparison between two patient collectives; target group = patients having a dominant/largest myoma with a diameter of $\geq 10 \mathrm{~cm}$; comparison group $=$ patients with a myoma $<10 \mathrm{~cm}$. The data were pro- 
cessed using SPSS 20.0. The Spearman correlation coefficient, Fisher's exact test and the exact Mantel-Haenszel test were used to test for relationships between the different parameters. For a comparison of the severity of complaints before and after the abdominal myoma enucleation, the exact Wilcoxon test for paired samples was used and the exact Mann-Whitney U test was used to check for differences in the independent variables. For all statistical tests a significance level of $\mathrm{p}$ (2-sided) $\leq 0.05$ was assumed.

The principles for good scientific practice and data protection set out in the charter of the Charité - University Medical School Berlin were strictly applied, the Institutional Board gave its approval for this study.

\section{Results \\ $\nabla$}

\section{Response rate and composition of the investigated collective}

Of the 377 patients who were operated on in the study period from February 2002 to December 2009, altogether 230 (response rate $61 \%$ ) returned the preoperative questionnaire and 245 (64.9\%) the postoperative questionnaires, 155 patients (41.1\%) completed both surveys. The postoperative survey was carried out between May and November 2010, whereby the patients were contacted by telephone on average $48.6 \pm 24.8$ months after their myoma operation and asked to participate in the survey. Once they had given their consent, the questionnaire was read to them by a female interviewer (T.K.) and the answers recorded. If the patients could not be reached by telephone the questionnaire was sent to them by post; $24 \%$ of the patients replied in this way. Patient data and answers were compared between those having myomas with a diameter greater than $10 \mathrm{~cm}$ and those with one of less than $10 \mathrm{~cm}$. The basis for group assignment was the parameter myoma size when this was unequivocally reported in the histopathological report: 65 patients $(20.1 \%)$ had a myoma with a diameter of $10 \mathrm{~cm}$ or more, 258 women (79.9\%) had smaller myomas (total $-n=323$ patients, missing $-n=54$ ). At the time of the myoma removal the patients were on average 37.4 years old (median 37.0) and had a BMI of 23.7 (=average; median: 22.7).

\section{Postoperative satisfaction and impairments in daily life} Although the postoperative haemoglobin values did not show any statistically significant difference between the two groups, the scar lengths (as measured by the patients) in the patient group with myomas $\geq 10 \mathrm{~cm}$ were larger (median values 10.0 vs. $8.0 \mathrm{~cm})$.

Details on the length of sick leave were available for 28 patients with myomas of at least $10 \mathrm{~cm}$ diameter and for 133 patients with smaller myomas. On average, the duration of sick leave for patients with a myoma diameter of $\geq 10 \mathrm{~cm}$ was 1.5 days shorter than that for patients with myomas $<10 \mathrm{~cm}$ ( $\diamond$ Table 1 ). Data are available for 39 patients with a myoma $\geq 10 \mathrm{~cm}$ on as to how long they felt that their activities of daily life were impaired after the operation. In the comparison group with smaller myomas, 157 women provided information on this aspect. Patients with myomas $\geq 10 \mathrm{~cm}$, according to their self reports, experienced impairments for 12 days less than the women with smaller myomas ( Table 1). For comparisons of the postoperative satisfaction, the three variables "postoperative well-being with regard to myoma complaints", "general health satisfaction" and "would you
Table 1 Postoperative haemoglobin ( $\mathrm{Hb}$ ) value and reported postoperative patient answers.

\begin{tabular}{|c|c|c|c|}
\hline & \multicolumn{2}{|c|}{$\begin{array}{l}\text { Diameter of the } \\
\text { largest myoma }\end{array}$} & \multirow[t]{2}{*}{$\begin{array}{l}\text { p Value } \\
\text { (2-sided) }\end{array}$} \\
\hline & $>10 \mathrm{~cm}$ & $<10 \mathrm{~cm}$ & \\
\hline Haemoglobin level (in g/dL) & & & 0.025 \\
\hline average & 9.6 & 10.2 & \\
\hline - median & 9.9 & 10.7 & \\
\hline$\checkmark \mathrm{SD}$ & 2.14 & 1.86 & \\
\hline minimum & 4.2 & 5.6 & \\
\hline maximum & 14.0 & 14.2 & \\
\hline Length of scar (in cm)* & & & $<0.001$ \\
\hline average & 10.92 & 8.11 & \\
\hline median & 10.0 & 8.00 & \\
\hline$>\mathrm{SD}$ & 4.29 & 3.19 & \\
\hline minimum & 5.0 & 3.0 & \\
\hline maximum & 25.0 & 20.0 & \\
\hline Duration of sick leave (in days) & & & 0.602 \\
\hline average & 30.46 & 31.96 & \\
\hline median & 28.00 & 28.00 & \\
\hline$\checkmark \mathrm{SD}$ & 17.274 & 18.056 & \\
\hline 25th percentile & 14.00 & 21.00 & \\
\hline 75th percentile & 42.00 & 42.00 & \\
\hline $\begin{array}{l}\text { Impairment in activities of daily } \\
\text { life (in days) }\end{array}$ & & & 0.538 \\
\hline average & 46.01 & 58.20 & \\
\hline median & 28.00 & 28.00 & \\
\hline$\checkmark \mathrm{SD}$ & 48.957 & 96.147 & \\
\hline 25th percentile & 14.00 & 14.00 & \\
\hline 75th percentile & 56.00 & 58.50 & \\
\hline $\begin{array}{l}\text { Postoperative well-being with } \\
\text { regard to myoma complaints } \\
\text { (scale scores**) }\end{array}$ & & & 0.130 \\
\hline average & 9.28 & 8.67 & \\
\hline - median & 10.00 & 10.00 & \\
\hline$\checkmark \mathrm{SD}$ & 1.256 & 2.061 & \\
\hline 25th percentile & 9.00 & 8.00 & \\
\hline 75th percentile & 10.00 & 10.00 & \\
\hline $\begin{array}{l}\text { General satisfaction with own } \\
\text { health (scale scores**) }\end{array}$ & & & 0.104 \\
\hline average & 8.08 & 7.49 & \\
\hline median & 8.00 & 8.00 & \\
\hline$\checkmark \mathrm{SD}$ & 1.962 & 2.014 & \\
\hline 25th percentile & 7.25 & 7.00 & \\
\hline 75th percentile & 10.00 & 10.00 & \\
\hline
\end{tabular}

SD = standard deviation; ${ }^{*}$ measured by the patients themselves; ${ }^{* *}$ scale: $0=$ not at all satisfied through to $10=$ maximum satisfaction

recommend the operation to a friend" were considered for the group comparison. Concerning the question "how do you feel now in comparison to your myoma-related complaints prior to the operation?" answers were available from 36 patients with a myoma diameter of $\geq 10 \mathrm{~cm}$ and from 156 patients with myomas $<10 \mathrm{~cm}$. Patients in the group with $\geq 10 \mathrm{~cm}$ myoma diameter gave about the same values on the scale from 0 (not at all satisfied) to 10 (maximum satisfaction) (no significant difference - Table 1) as did those with smaller myomas. A scale of 0-10 was also used to characterise the general health satisfaction. Here also there were no relevant differences in scores between the two groups (see $\odot$ Table 1, no significant difference).

Patients in both investigated groups would recommend the operation to a friend in about the same proportions (no statistically significant difference between the two myoma size groups; - Table 2). 
Table 2 Comparison: Would you recommendation the operation?

\begin{tabular}{|c|c|c|c|c|}
\hline \multirow[t]{3}{*}{ Diameter of the largest myoma } & \multicolumn{4}{|c|}{ Recommend the operation to a friend } \\
\hline & No & Yes & Don’t know & Total \\
\hline & $n(\%)$ & n (\%) & n (\%) & n (\%) \\
\hline$\geq 10 \mathrm{~cm}$ & $2(5.1)$ & $31(79.5)$ & $6(15.4)$ & $39(100.0)$ \\
\hline $10 \mathrm{~cm}$ & $15(9.0)$ & $134(80.7)$ & $17(10.2)$ & $166(100.0)$ \\
\hline total & $17(8.3)$ & $165(80.5)$ & $23(11.2)$ & $205(100.0)$ \\
\hline$p=0.560$ & & & & \\
\hline
\end{tabular}

Table 3 Pre- and postoperative severity of symptoms in the participating patients in dependence on myoma size (grouped scale scores).

\begin{tabular}{|c|c|c|c|c|c|c|}
\hline \multirow{4}{*}{ Myoma size } & \multicolumn{6}{|c|}{ Severity of complaints } \\
\hline & \multicolumn{2}{|c|}{$0-3$ (mild) } & \multicolumn{2}{|c|}{ 4-6 (moderate) } & \multicolumn{2}{|c|}{ 7-8 (severe) } \\
\hline & $<10 \mathrm{~cm}$ & $\geq 10 \mathrm{~cm}$ & $<10 \mathrm{~cm}$ & $\geq 10 \mathrm{~cm}$ & $<10 \mathrm{~cm}$ & $\geq 10 \mathrm{~cm}$ \\
\hline & $\mathrm{n}(\%)$ & n (\%) & n (\%) & $n(\%)$ & $\mathrm{n}(\%)$ & n (\%) \\
\hline \multicolumn{7}{|l|}{ Preoperative } \\
\hline Severity of bleeding & $16(10.6)$ & $9(32.1)$ & $47(31.1)$ & $9(32.1)$ & $88(58.3)$ & $10(35.7)$ \\
\hline Pain during menstrual bleeding & $81(50.6)$ & $18(60.0)$ & $44(27.5)$ & $7(23.2)$ & 35 (21.9) & $5(16.7)$ \\
\hline Pain during sexual intercourse & $120(78.4)$ & $24(85.7)$ & $23(15.0)$ & $2(7.1)$ & $10(6.5)$ & $2(7.1)$ \\
\hline Pressure in the bladder & $84(52.5)$ & $18(60.0)$ & $44(27.5)$ & $5(16.7)$ & $32(20.0)$ & $7(23.3)$ \\
\hline Foreign body feeling in lower abdomen & $91(57.6)$ & $19(65.5)$ & $40(25.3)$ & $4(13.8)$ & $27(17.1)$ & $6(20.7)$ \\
\hline \multicolumn{7}{|l|}{ Postoperative } \\
\hline Severity of bleeding & $43(28.5)$ & $10(28.6)$ & $79(52.3)$ & $18(51.4)$ & $29(19.2)$ & $7(20.0)$ \\
\hline Pain during menstrual bleeding & $102(66.7)$ & $25(71.4)$ & $27(17.6)$ & $6(17.1)$ & $24(15.7)$ & $4(11.4)$ \\
\hline Pain during sexual intercourse & $136(88.3)$ & $38(100)$ & $15(9.7)$ & $0(0)$ & $3(1.9)$ & $0(0)$ \\
\hline Pressure in the bladder & $128(77.6)$ & $35(89.7)$ & $23(13.9)$ & $4(10.3)$ & $14(8.5)$ & $0(0)$ \\
\hline Foreign body feeling in lower abdomen & $136(82.9)$ & $36(94.7)$ & $20(12.2)$ & $2(5.3)$ & $8(4.9)$ & $0(0)$ \\
\hline
\end{tabular}

\section{Improvement of complaints}

The success of the open abdominal myoma enucleation was assessed with regard to the changes or, respectively, improvements of the symptom severity of bleeding, pain during the period, feeling of pressure in the bladder, pain during sexual intercourse, and feeling of a foreign body in the lower abdomen. Those patients in whom the operation was performed exclusively to improve fertility in accord with a desire to have children were excluded from this analysis. Due to the different response rates by the myoma patients to the questionnaires supplied prior to and after the operation, the number of evaluable cases is smaller compared to the total sample. The values on the symptom scale were grouped ( mild $=0-3$, moderate $=4-7$, severe complaints $=8-10$ ) and evaluated for the pre- and postoperative time points ( $\bullet$ Table 3 ). The target parameter was defined as the change (symptoms better, symptoms worse, symptoms unchanged) between the two investigated time points before and after myoma removal. For this prepost comparison the complaints were also summarised in the same groups as above. Changes within the predefined scale ranges $(0-3,4-7,8-10)$ were not considered to be relevant changes. The results are given in 0 Table 4 . An improvement in complaints, depending on the symptom, could be detected in between 7 and $75 \%$ of the patients. Among the patients with myomas $\geq 10 \mathrm{~cm}$, the proportion of women with an improvement in symptoms was generally lower than that among patients with smaller myomas, with the exception of the parameter "feeling of pressure in the bladder". A significant difference between the two groups (in favour of the myoma $<10 \mathrm{~cm}$ group) was only seen for the improvement in the severity of bleeding $(p=0.002)$.

Table 4 Changes in myoma-associated complaints - comparison of status before and after myoma enucleation ( $p$ values refer to the comparison between patients with improved symptoms vs. patients in unchanged or poorer condition).

\begin{tabular}{|c|c|c|c|c|c|c|c|c|c|c|}
\hline \multirow[b]{2}{*}{ Myoma size } & \multicolumn{2}{|c|}{ Severity of bleeding } & \multicolumn{2}{|c|}{$\begin{array}{l}\text { Severity of pain dur- } \\
\text { ing period bleeding }\end{array}$} & \multicolumn{2}{|c|}{$\begin{array}{l}\text { Pressure feeling } \\
\text { in bladder }\end{array}$} & \multicolumn{2}{|c|}{$\begin{array}{l}\text { Pain during } \\
\text { sexual intercourse }\end{array}$} & \multicolumn{2}{|c|}{$\begin{array}{l}\text { Foreign body feeling } \\
\text { in lower abdomen }\end{array}$} \\
\hline & $\begin{array}{l}<10 \mathrm{~cm} \\
(\mathrm{n}=67)\end{array}$ & $\begin{array}{l}\geq 10 \mathrm{~cm} \\
(\mathrm{n}=14)\end{array}$ & $\begin{array}{l}<10 \mathrm{~cm} \\
(\mathrm{n}=69)\end{array}$ & $\begin{array}{l}\geq 10 \mathrm{~cm} \\
(\mathrm{n}=15)\end{array}$ & $\begin{array}{l}<10 \mathrm{~cm} \\
(\mathrm{n}=108)\end{array}$ & $\begin{array}{l}\geq 10 \mathrm{~cm} \\
(\mathrm{n}=17)\end{array}$ & $\begin{array}{l}<10 \mathrm{~cm} \\
(\mathrm{n}=96)\end{array}$ & $\begin{array}{l}\geq 10 \mathrm{~cm} \\
(\mathrm{n}=15)\end{array}$ & $\begin{array}{l}<10 \mathrm{~cm} \\
(\mathrm{n}=108)\end{array}$ & $\begin{array}{l}\geq 10 \mathrm{~cm} \\
(\mathrm{n}=16)\end{array}$ \\
\hline \multicolumn{11}{|l|}{ Symptom } \\
\hline better & 74.6 & 28.6 & 39.1 & 20.0 & 32.4 & 41.2 & 16.7 & 6.7 & 39.8 & 37.5 \\
\hline poorer & 10.4 & 35.7 & 33.3 & 33.3 & 10.2 & 11.8 & 5.2 & 0 & 10.2 & 0 \\
\hline - unchanged & 24.9 & 35.7 & 27.5 & 46.7 & 57.4 & 47.1 & 78.1 & 93.3 & 50.0 & 62.5 \\
\hline p Value & & 0.002 & & 0.234 & & 0.581 & & 0.459 & & 1.000 \\
\hline
\end{tabular}




\section{Discussion}

$\nabla$

The period up to a return to work or, respectively, to a (complete) recovery of capabilities after a gynaecological operation is often relatively long - irrespective of whether the operation was carried out for a benign finding, and only slightly influenced by the fact that minimally invasive surgical techniques and other improvements in perioperative management have markedly reduced the morbidity in comparison to earlier decades. Lengthening of the interval until full recovery and return to work reduces the patient's quality of life and leads to unnecessary costs for society due to loss of working time, additional medical consultations and increased consumption of medications. Patients with a lengthened recovery period up to return to work after gynaecological operations reported in a study from Birmingham (UK) above all of pain, anxiety, depressions and infections as the main causes for the prolonged convalescence period [12].

Although the study results are based partly on retrospectively evaluated data, the combination of data from pre- and postoperative questionnaires together with clinical data provide important findings on the as yet sparsely investigated postoperative course of female patients after open abdominal myoma enucleation. The study results reveal some statistically and clinically relevant relationships between myoma size and the improvement of complaints or, respectively, postoperative impairments in activities of daily life.

The postoperative satisfaction of a patient with the therapy and the result of the treatment is an important criterion for the quality of a treatment procedure. In our study we used three questions to assess just this aspect: improvement of the myoma-related complaints, general health satisfaction, and recommendation of the operation to a friend. The size of the removed myoma does not appear, according to the results of our analyses, to play a decisive role; in each group about 4/5 of our patients were so satisfied with the therapy that they would recommend such a myoma enucleation to their friends. This result confirms the findings from two studies, one in London and one in a Nigerian university hospital, showing that a very large uterus myomatosus is not necessarily associated with a significantly higher morbidity [13, $14]$.

Goodwin et al. (2006) published the results of a prospective study carried out in Los Angeles (USA) comparing the quality of life after myoma removal by laparotomy with that after uterine artery embolisation (UAE): For both groups the average postoperative sick leave amounted to 37.0 days, and thus was about one week longer than for the patients in our study [15]. Wang et al. (2013) in the course of a randomised clinical trial compared the treatment of myoma patients in a Chinese university hospital by focused ultrasound with treatment by open abdominal myoma removal. In the group undergoing surgery $(n=52)$ the women on average could resume normal activities of daily life already after 15 (7-60) days [16]. This period was markedly longer in the current study (median 28 days). Razavi et al. (2003), in the course of a study performed in Stanford (USA) that investigated the therapeutic success and complication rates between open abdominal myoma enucleation and UAE, reported that patients in the surgery group could resume activities of daily life on average after 36 days [17]. Evenson et al. (2012) interviewed 127 women in Salt Lake City/USA at one, two and six weeks after a vaginal or an open abdominal gynaecological operation with a focus on the need for pain killers. Here about half of the interviewed women considered themselves to be postoperatively recovered and two thirds to be "normal again" at six weeks after surgery [18].

When not exclusively concerned with an improvement of the fertility situation, the principle objective of measures to treat a myoma is to achieve relief from the complaints. Razavi et al. (2003) in their already mentioned study found an improvement in menorrhagia in $64 \%$ (14/22) of their patients at about 15 months after surgical myoma enucleation and 54\% (14/26) of the women reported less pain postoperatively [17]. Wen et al. (2011) compared the therapeutic results of patients in a Taiwan university hospital after myoma enucleation by conventional laparotomy with those after the so-called ultraminilaparotomy. One year after the operation, 45 of 46 patients (98\%) experienced an improvement of their bleeding problems and 41 of 43 (95\%) an improvement of period-associated pain [19]. Otherwise in the literature mainly improvements in the general symptoms are reported. These include $75-90 \%$ reduction of symptoms in follow-up periods of between 6 months and $\geq 3$ years [10,20-22].

Independent of the size of the myoma, the open abdominal myoma enucleation leads to a high postoperative satisfaction among those patients who, after appropriate medical consultation and clarification, chose this method of treatment. In most cases, a smaller proportion of the women with a myoma $\geq 10 \mathrm{~cm}$ experienced a postoperative improvement of their symptoms. However, a significant difference with regard to improvement of symptoms was only observed in the severity of bleeding. Here patients with myomas $<10 \mathrm{~cm}$ appear to have a greater benefit from the operation. In comparison with the international literature, the average duration of sick leave in our patients was in the middle of the range.

Limitations of our study: we could approach a relatively large patient collective, however, the response rates of the patient questionnaires were, in consideration of the actual setting and the time elapsed since the operation, not optimal but could be considered as being relatively high [23]. Since all the operations were performed by one and the same surgeon, any bias due to differing surgical approaches can practically be excluded, on the other hand, however, this individual operative technique has, as yet, not been compared with those used in other studies. The informative value of our study results is limited by the lack of an actual control group and the retrospective study design. The in part relatively long intervals between the time point of the operation and the postoperative questioning could have had a negative influence on the validity of our data. Furthermore, data acquisition on the myoma-related complaints did not involve the internationally frequently used questionnaire, namely the Uterine-Fibroid-Symptom-and-Quality-of-Life (UFS-QOL) [24], but rather a self-developed Likert scale and questionnaire. Because of the relatively long follow-up period it cannot be excluded that some of the patients may have developed new myomas which could have had a negative impact on their assessment of the therapeutic success (improvement of complaints). The consolidated assessment of the symptom scale scores into three groups levels out small improvements in the myoma-related complaints.

An ultimate goal is a prospective data acquisition with a systematic postoperative follow-up questioning of a large group of patients after gynaecological operations such as, for example, myoma enucleation [25], in order to gain objective data not only, for example, to determine the necessary duration of sick leave but also to formulate recommendations as to when what physical loads and daily activities can be resumed. 


\section{Conflict of Interest}

$\nabla$

None.

\section{References}

1 Reitsma ML, Vandenkerkhof EG, Johnston SL et al. Does health-related quality of life improve in women following gynaecological surgery. J Obstet Gynaecol Can 2011; 33: 1241-1247

2 Baird DD, Dunson DB, Hill MC et al. High cumulative incidence of uterine leiomyoma in black and white women: ultrasound evidence. Am J Obstet Gynecol 2003; 188: 100-107

3 Buttram VC, Reiter RC. Uterine leiomyomata: etiology, symptomatology, and management. Fertil Steril 1981; 36: 433-445

4 Gupta S, Jose J, Manyonda I. Clinical presentation of fibroids. Best Pract Res Clin Obstet Gynaecol 2008; 22: 615-626

5 Borah BJ, Nicholson WK, Bradley L et al. The impact of uterine leiomyomas: a national survey of affected women. Am J Obstet Gynecol 2013; 209: 319.e1-319.e20

6 Péréz-López FR, Ornat L, Ceausu I et al. EMAS position statement: management of uterine fibroids. Maturitas 2014; 79: 106-116

7 Harding G, Coyne KS, Thompson CL et al. The responsiveness of the uterine fibroid symptom and health-related quality of life questionnaire (UFS-QOL). Health Qual Life Outcomes 2008; 6: 99

8 Scheurig-Münkler C, David M, Kröncke TJ. Uterusarterienembolisation bei Patientinnen mit symptomatischen Gebärmuttermyomen: prospektive Studie zu klinischem Erfolg und Veränderung der Lebensqualität im langfristigen Verlauf. Geburtsh Frauenheilk 2011; 71: 653-658

9 Darwish M, Atlantis E, Mohamed-Taysir T. Psychological outcomes after hysterectomy for benign conditions: a systematic review and metaanalysis. Eur J Obstet Gynecol Reprod Biol 2014; 174: 5-19

10 Horng $H C$, Wen $K C$, Su WH et al. Review of myomectomy. Taiwan J Obstet Gynecol 2012; 51: 7-11

11 Jonmarker S, Valdman A, Lindberg A et al. Tissue shrinkage after fixation with formalin injection of prostatectomy specimens. Virchows Arch 2006; 449: 297-301

12 Clayton M, Verow P. A retrospective study of return to work following surgery. Occup Med (Lond) 2007; 57: 525-531

13 Pundir J, Krishnan N, Siozos A et al. Peri-operative morbidity associated with abdominal myomectomy for very large fibroid uteri. Eur J Obstet Gynecol Reprod Biol 2013; 167: 219-224
14 Oladapo OT, Akinsanya AF. Relative morbidity of abdominal myomectomy for very large uterine fibroids in a developing country hospital. Arch Gynecol Obstet 2011; 283: 825-830

15 Goodwin SC, Bradley LD, Lipman JC et al. Uterine artery embolization versus myomectomy: a multicenter comparative study. Fertil Steril 2006; 85: 14-21

16 Wang X, Qin J, Wang L et al. Effect of high-intensity focused ultrasound on sexual function in the treatment of uterine fibroids: comparison to conventional myomectomy. Arch Gynecol Obstet 2013; 288: 851-858

17 Razavi MK, Hwang G, Jahed $A$ et al. Abdominal myomectomy versus uterine fibroid embolization in the treatment of symptomatic uterine leiomyomas. AJR 2003; 180: 1571-1575

18 Evenson M, Payne D, Nygaard I. Recovery at home after major gynecologic surgery: How do our patients fare? Obstet Gynecol 2012; 119: 780-784

19 Wen KC, Sung PL, Chao KC et al. A prospective short-term evaluation of uterine leiomyomas treated by myomectomy through conventional laparotomy or ultraminilaparotomy. Fertil Steril 2008; 90: 2361-2366

20 Broder MS, Goodwin S, Chen G et al. Comparison of long-term outcomes of myomectomy and uterine artery embolization. Obstet Gynecol 2002; 100: 864-868

21 Mara M, Maskova J, Fucikova Z et al. Midterm clinical and first reproductive results of a randomized controlled trial comparing uterine fibroid embolization and myomectomy. Cardiovascul Intervent Radiol 2008; 31: 73-85

22 Siskin GP, Shlansky-Goldberg RD, Goodwin SC et al. A prospective multicenter comparative study between myomectomy and uterine artery embolization with polyvinyl alcohol microspheres: long-term clinical outcomes in patients with symptomatic uterine fibroids. J Vasc Interv Radiol 2006; 17: 1287-1295

23 Koch K, Schürmann C, Sawicki P. Das deutsche Gesundheitswesen im internationalen Vergleich. Dtsch Arztebl Int 2010; 107: 427-434

24 Spies JB, Coyne K, Guaou Guaou N et al. The UFS-QOL, a new diseasespecific symptom and health-related quality of life questionnaire for leiomyomata. Obstet Gynecol 2002; 99: 290-300

25 Vonk Noordegraaf A, Anema JR, Louwerse MD et al. Prediction of time to return to work after gynaecological surgery: a prospective cohort study in the Netherlands. BJOG 2014; 121: 487-497 